\title{
MULTICOMPONENT POLYMER SYSTEM BASED ON HYDROPHILIZED UNSATURATED POLYESTER RESIN
}

\author{
Rumyana Cherkezova ${ }^{1}$, Tatyana Hristova ${ }^{1}, K_{r i s t i n a ~ Z a f i r o v a}{ }^{1}$, Anton Popov $^{2}$, \\ Maksim Simov \\ ${ }^{1}$ Department of Medical and Biological Sciences, Faculty of Medicine, \\ Medical University of Varna \\ ${ }^{2}$ University "Prof. A. Zlatarov", Burgas \\ ${ }^{3}$ TRS Dental Technician, Medical College, Medical University of Varna
}

\begin{abstract}
This work is a follow-up of the study of hydrophilization of unsaturated polyester resin (UPER) with sodium hydroxide. Different amounts of water were added to the hydrophilized unsaturated polyester resin (HUPER) so obtained and their effects on curing kinetics were studied. The tensile strength and energy to break these compositions are presented depending on the amount of the specified components. A possibility for using different fillers, coal ash in particular, and their mixing with HUPER was sought. The effect of each of the components on the curing kinetics of the respective compositions, and the effect of all components when consecutively mixed in the multicomponent composition was examined. We sought an opportunity for the application of some of the compositions as substituents of dental cast models.
\end{abstract}

Keywords: unsaturated polyester resin, hydrophilization, sodium hydroxide, coal ash

\section{INTRODUCTION}

Unsaturated polyester resins are useful for construction and architecture, especially when used as composite materials, thereby mitigating the drawbacks of their individual application. So far, there are studies that examine: obtaining of unsaturated polyester resins (1,2), polymer concrete (3), and alkyd resins, in relation to ecology and environmental protection; use of glass fibers as a molding material and addition of slag to UPER, which, in an appropriate mixing proportion, gains composite properties with good strength parameters (4); use of waste ash dust as

Address for correspondence:

Rumyana Cherkezova

Faculty of Medicine

Medical University of Varna

55 Marin Drinov St

9002 Varna

e-mail:Rumiana.Cherkezova@mu-varna.bg

Received: March 9, 2017

Accepted: May 19, 2017 a filler significantly affecting the temperature relaxation behavior of the polymer composite, which demonstrates significant increase in the tensile modulus of the material and decrease in its tensile strength at various temperatures (5). Another solution for using unsaturated polyester resins is to put them into multicomponent polymer systems, in which the resin is hydrophilized and thereby gains valuable properties not only mixing with water but also with other fillers (6) in various application aspects. Hydrophilizing reagents, such as sodium hydroxide and sulfur, were sought to attack ester linkages in the macromolecules, to fragment them and affect the number of carboxyl groups. The concentration of these hydrophilizing reagents affects the dynamics of polymerization processes, as they are accelerated when used moderately (7).

The purpose of this work is to obtain multicomponent polymer systems based on HUPER, ability to dissolve in water of the compositions obtained and to fill them with coal ash, without slowing down their curing kinetics in particular proportions. 
Rumyana Cherkezova, Tatyana Hristova, Kristina Zafirova et al.

\section{MATERIALS AND METHODS}

\section{Materials}

We have used resin of type Vinalkyd 550 PE-R (Orgachim Resins - Ruse) containing 35\% styrene and $65 \%$ unsaturated polyesters, which is a polycondensation product of propylene glycol and maleic anhydride. A 50\% solution of cyclohexanone peroxide (CHP) in dibutylphthalate was used as a curing initiator, and a $10 \%$ solution of cobalt naphthenate $(\mathrm{CN})$ in styrene was the accelerator. Waste material obtained from coal combustion was used - coal ash (CA). Sulfur in powder form (S) was added.

\section{Methods}

The methods for obtaining multicomponent polymer compositions were in the following particular order of adding the ingredients: UPER, $\mathrm{NaOH}$, $\mathrm{CA}, \mathrm{S}, \mathrm{H}_{2} \mathrm{O}, \mathrm{CN}$, and $\mathrm{CHP}$.

The tensile strength and energy to break were determined on INSTRON dynamometer, model 4203 (UK), at a speed of $10 \mathrm{~mm} / \mathrm{min}$ and room temperature.

\section{RESULTS AND DISCUSSION}

Polymer compositions based on UPER were obtained using the hydrophilizing reagent $\mathrm{NaOH}$. To that effect, different amounts of $33 \% \mathrm{NaOH}$ were added in drops to a specific quantity of resin. The purpose of that hydrophilizer was to ionize the free carboxyl groups of the unsaturated polyester chain resulting in probably fragmented sections of sodium salts. The process takes place with continuous and intensive stirring and consecutive addition of components one after another, in the specified order.

Table 1 represents the compositions for obtaining HUPER at different amounts of $\mathrm{NaOH}$.

The time from obtaining the mixture to the curing point was traced as a function of the heat that Table 1. Effect of $\mathrm{NaOH}$ amount on polymerization activity of the hydrophilized resin. Amounts: $30 \mathrm{~g}$ UPER; $1.2 \mathrm{ml}$ $\mathrm{CHP} ; 0.6 \mathrm{ml} \mathrm{CN}$

\begin{tabular}{|c|ccc|}
\hline $\begin{array}{l}\text { Sample } \\
\text { number }\end{array}$ & $\begin{array}{c}\text { Amount } \\
33 \% \mathrm{NaOH}, \mathrm{ml}\end{array}$ & $\begin{array}{c}\text { Time } \\
{[\tau, \mathrm{min}]}\end{array}$ & $\begin{array}{c}\text { Temperature } \\
{\left[\text { Tmax },{ }^{\circ} \mathrm{C}\right]}\end{array}$ \\
\hline 1 & 0.2 & 10 & 168 \\
2 & 0.4 & 14 & 158.5 \\
3 & 0.6 & 18 & 153.5 \\
4 & 0.8 & 18 & 153.5 \\
5 & 1.0 & 14 & 147.5 \\
\hline
\end{tabular}

is released upon reaching the maximum temperature. It is thus possible to obtain the respective kinetic dependencies according to the Hess's law - it is known that, due to the exothermic curing process, the temperature rise over time will correspond to the cross-linking rate (curing kinetics).

Figure 1 shows the kinetic dependencies of processes when the temperature changes over time until the curing point at different quantities of $\mathrm{NaOH}$, according to Table 1 .

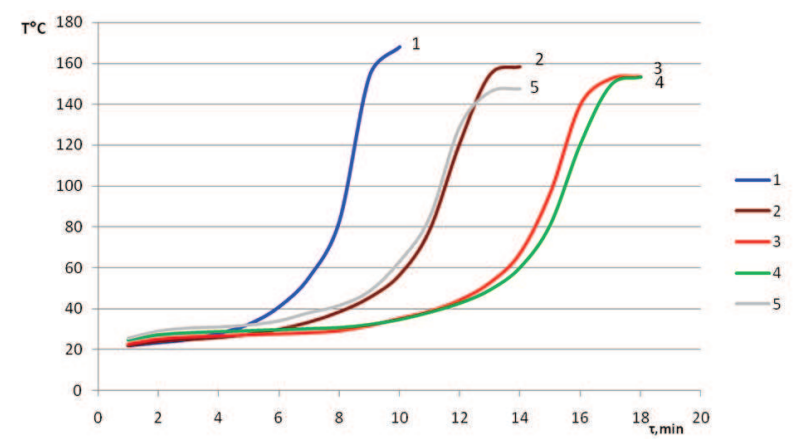

Figure 1. Kinetics of the polymerization process, where: curve $1-0.2 \mathrm{ml} \mathrm{NaOH}$; curve $2-0.4 \mathrm{ml} \mathrm{NaOH}$; curve 3 - $0.6 \mathrm{ml} \mathrm{NaOH}$; curve 4 - $0.8 \mathrm{ml} \mathrm{NaOH}$; curve 5 - $1.0 \mathrm{ml}$ $\mathrm{NaOH}$

The tensile strength and energy of break of the compositions in Table 1 were measured, as shown on Figure 2 and Figure 3.

Figure 2 shows that the percentage of $\mathrm{NaOH}$ has an extreme dependency that is expressed in passing through the minimum tensile strength for $0.6 \mathrm{ml}$ $33 \% \mathrm{NaOH}$. For the other compositions, the change in that indicator is smooth, as it is insignificantly affected after $0.8 \mathrm{ml} 33 \% \mathrm{NaOH}$.

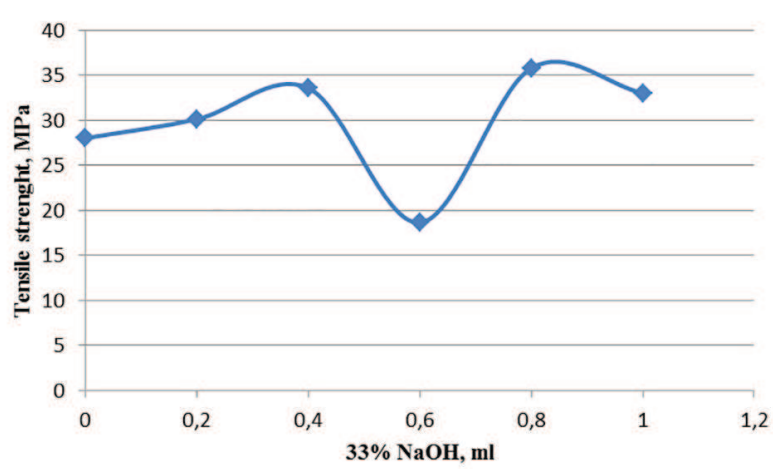

Figure 2. Tensile strength data depending on the change in $\mathrm{NaOH}$ 
Multicomponent Polymer System Based on Hydrophilized Unsaturated Polyester Resin

There is a similar dependency in the energy of break, which does not change smoothly with the increase in the precentage of $\mathrm{NaOH}$ but passess through the minimum point again $(0.6 \mathrm{ml} 33 \% \mathrm{NaOH})$.

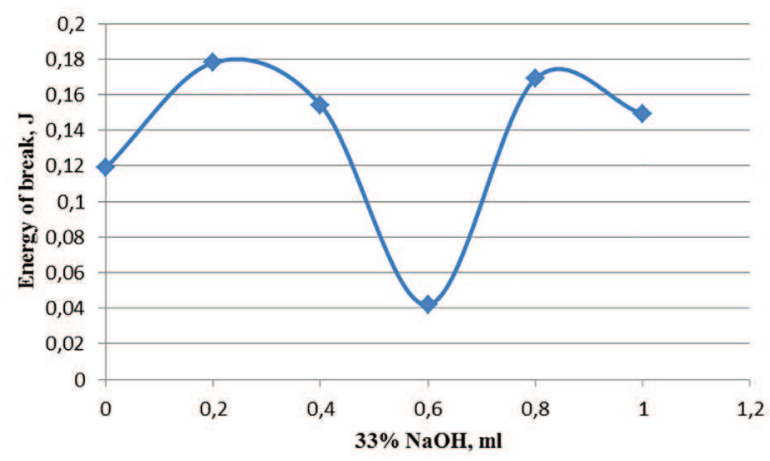

Figure 3. Energy of break data depending on the change in $\mathrm{NaOH}$

The addition of $\mathrm{NaOH}$ plays the role of hydrophilizer of the resin, thereby it is possible to add water, which serves as a solvent on the one hand, but on the other hand acts as a homogenizing medium up to a certain quantity. The water is added immediately after the hydrophilizer with continuous stirring. Finally, we add the redox system.

The possibilities of adding water at a constant quantity of sodium hydroxide were traced and it was found that the amount of water can be changed in different ranges, from 3 to $20 \%$ in this particular case. This is shown in Table 2.

Figure 4 shows the kinetic dependencies of processes when the temperature changes over time until the curing point with the change in the water amount, according to Table 2 .

The figure shows that the addition of certain amounts of water, from 1 to $5 \mathrm{~g}$, to a preselected com-

Table 2. Effect of the water amount on the polymerization activity of the hydrophilized resin. Amounts: $30 \mathrm{~g}$ UPER;

$1.2 \mathrm{ml} \mathrm{CHP}$; $0.6 \mathrm{ml} \mathrm{CN}$; $0.6 \mathrm{ml} 33 \% \mathrm{NaOH}$

\begin{tabular}{l|ccc}
$\begin{array}{l}\text { Sample } \\
\text { number }\end{array}$ & $\begin{array}{c}\text { Amount of } \\
\text { water, } g\end{array}$ & $\begin{array}{c}\text { Time } \\
{[\tau, \min ]}\end{array}$ & $\begin{array}{c}\text { Temperature } \\
{\left[\text { Tmax, }{ }^{\circ} \mathrm{C}\right]}\end{array}$ \\
1 & - & 18 & 153.5 \\
2 & 1 & 22 & 145 \\
3 & 2 & 23 & 141 \\
4 & 3 & 19 & 137.5 \\
5 & 4 & 20 & 125.5 \\
6 & 5 & 21 & 121 \\
\hline
\end{tabular}

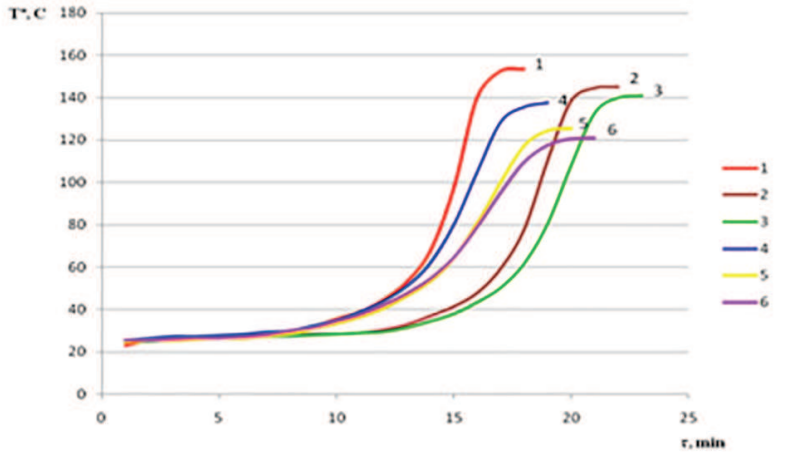

Figure 4. Kinetics of the polymerization process, where: curve 1 - $0.6 \mathrm{ml} \mathrm{NaOH}$; curve 2 - $1 \mathrm{~g} \mathrm{H}_{2} \mathrm{O}$; curve 3 - $2 \mathrm{~g}$ $\mathrm{H}_{2} \mathrm{O}$; curve 4 - $3 \mathrm{~g} \mathrm{H}_{2} \mathrm{O}$; curve 5 - $4 \mathrm{~g} \mathrm{H}_{2} \mathrm{O}$; curve 6 - $5 \mathrm{~g}$

$$
\mathrm{H}_{2} \mathrm{O}
$$

position results in a significant change in Tmax (approx. $30^{\circ} \mathrm{C}$ ), while the curing point changes slightly.

The tensile strength and energy of break of the compositions in Table 2 were measured, as shown on Figure 5 and Figure 6.

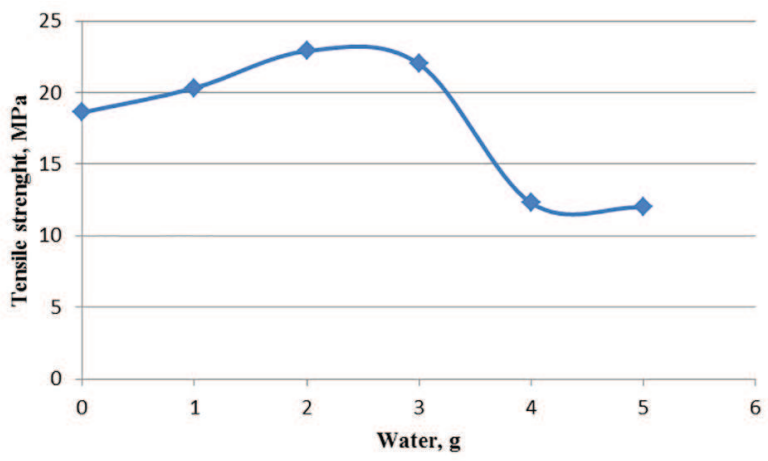

Figure 5. Tensile strength data depending on the change in the amount of water added

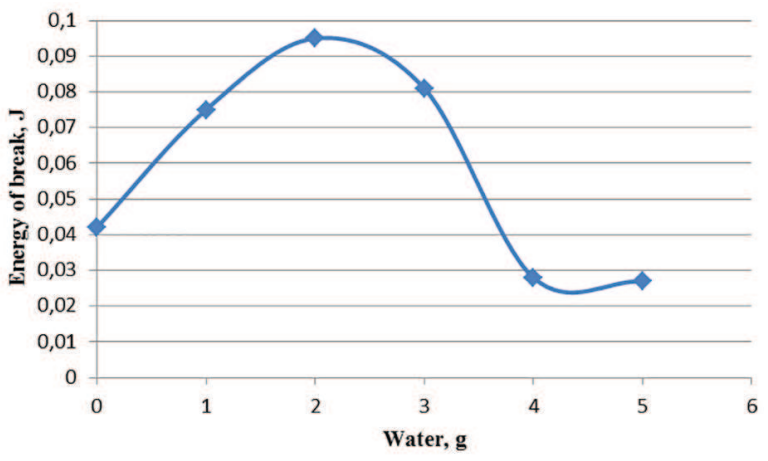

Figure 6. Energy of break data depending on the change in the amount of water added

The graphic dependencies demonstrate that an increase in the water amount changes the strength values to the extreme, as that dependency is the most 
Rumyana Cherkezova, Tatyana Hristova, Kristina Zafirova et al.

distinct at $4 \mathrm{~g}$ of water. The strength values decrease with higher amounts of water. Therefore, a possibility was sought to use appropriate fillers to strengthen the polymer matrix containing large amounts of water, which also makes them cheaper products.

In this work, coal ash is used as a filler. The effect of CA amount is traced at constant amount of $\mathrm{NaOH}$ and the resulting various compositions are presented in Table 3.

Table 3. Effect of the amount of coal ash on the polymerization activity of the hydrophilized resin. Amounts: $30 \mathrm{~g}$

UPER; $1.2 \mathrm{ml}$ CHP; $0.6 \mathrm{ml} \mathrm{CN}$; $0.6 \mathrm{ml} 33 \% \mathrm{NaOH}$

\begin{tabular}{lccc}
$\begin{array}{l}\text { Sample } \\
\text { number }\end{array}$ & $\begin{array}{c}\text { Amount of } \\
\text { coal ash, } g\end{array}$ & $\begin{array}{c}\text { Time } \\
{[\tau, \text { min] }}\end{array}$ & $\begin{array}{c}\text { Temperature } \\
\left.\text { [Tmax, }{ }^{\circ} \mathrm{C}\right]\end{array}$ \\
1 & - & 18 & 153.5 \\
2 & 0.2 & 18 & 153 \\
3 & 0.4 & 19 & 152.5 \\
4 & 0.6 & 20 & 149.5 \\
5 & 0.8 & 18 & 148.5 \\
6 & 1 & 20 & 148.5 \\
\hline
\end{tabular}

Figure 7 shows the kinetic dependencies when the temperature changes over time until the curing point with various amounts of $\mathrm{CA}$, according to Table 3 .

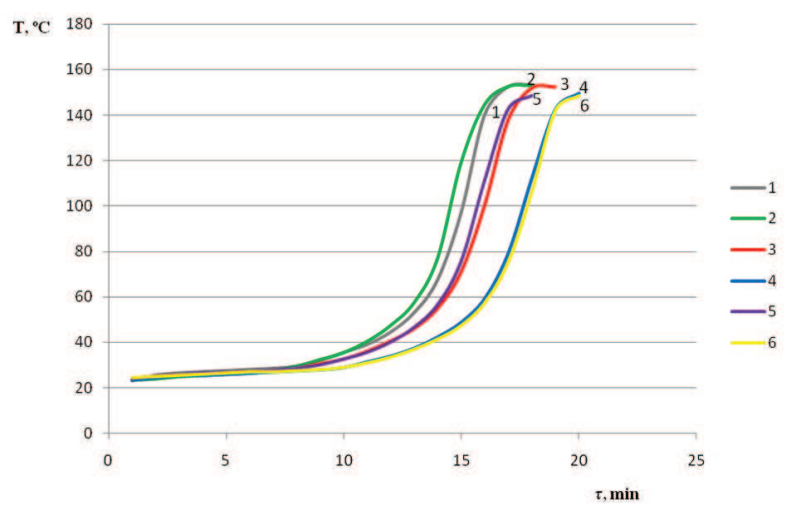

Figure 7. Kinetics of polymerization process, where: curve 1 - $0.6 \mathrm{ml} \mathrm{NaOH}$; curve 2 - $0.2 \mathrm{~g} \mathrm{CA}$; curve 3 - $0.4 \mathrm{~g} \mathrm{CA}$; curve 4 - $0.6 \mathrm{~g} C A$; curve 5 - $0.8 \mathrm{~g} C A$; curve 6 - $1 \mathrm{~g} C A$

It follows from the kinetic curves that the increase in the amount of CA does not significantly change the curing temperature and the curing point. This makes it possible to trace the effect of water even in higher amounts of $\mathrm{CA}$, e.g. for the composition: 30 g UPER; $1.2 \mathrm{ml} \mathrm{CHP;} 0.6 \mathrm{ml} \mathrm{CN}$; $0.6 \mathrm{ml} \mathrm{33 \%} \mathrm{NaOH}$; $1 \mathrm{~g}$ coal ash. Figure 8 shows the kinetic dependen- cies when the temperature changes over time until the curing point of three compositions, comprising successively $\mathrm{NaOH}(1)$, specific amount of CA (2) and the respective amount of water (3).

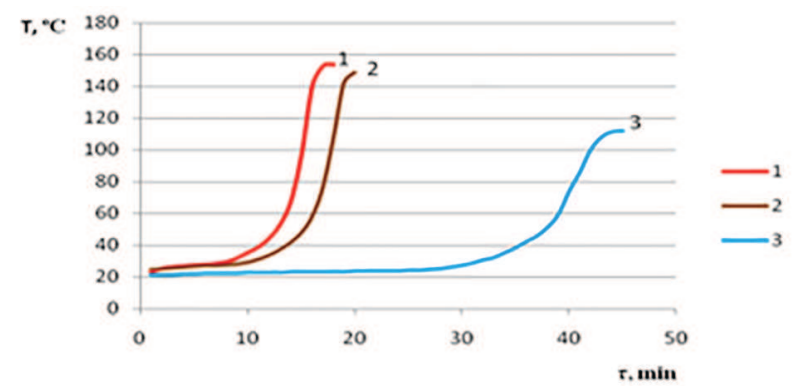

Figure 8. Kinetics of polymerization process, where: curve 1 - $0.6 \mathrm{ml} \mathrm{NaOH}$; curve 2 - $0.6 \mathrm{ml} \mathrm{NaOH}, 1 \mathrm{~g} \mathrm{CA}$; curve 3 - $0.6 \mathrm{ml} \mathrm{NaOH}, 1 \mathrm{~g} \mathrm{CA}, 5 \mathrm{~g}$ water

Figures 9 and 10 show cast teeth models specifying the volume changes of the material $-0.8 \%$ and $1 \%$, respectively.

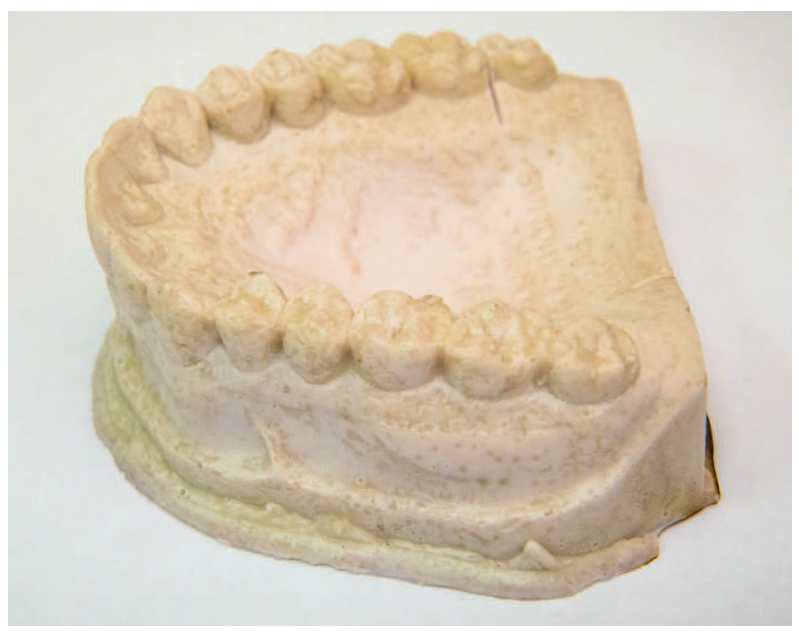

Figure 9. Cast teeth model of composition 6 from Table 2

\section{CONCLUSION}

Polymer compositions based on HUPER were developed using $33 \% \mathrm{NaOH}$ as a hydrophilizer in different quantities. The kinetics of polymerization process of different compositions is presented and their mechanical indicators, tensile strength and energy of break, were measured.

We developed polymer compositions comprising different amounts of water, which could be added in a wide range, and presented one of them (at 0.6 $\mathrm{ml} \mathrm{NaOH}$ ) with a range from 3 to $20 \%$ of water. It is shown by means of kinetic dependencies that those 


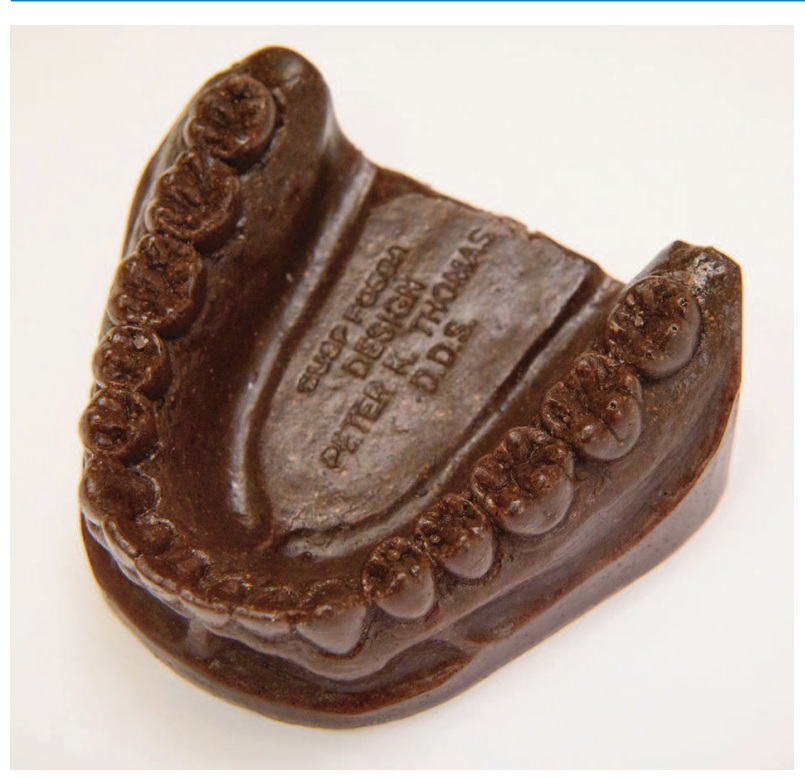

Figure 10. Cast teeth model of composition 6 from Table 3

quantities not only dilute and homogenize the system but also do not prevent its curing. The relevant mechanical indicators were measured.

Different possibilities for filling the hydrophilic polymer compositions with fillers, coal ash in particular, were looked into and the possibilities for their effects on the process kinetics. Forecasts for future studies of mechanical indicators of new compositions were made in the absence and presence of water in order to obtain cheaper and higher-strength products.

The multicomponent hydrophilized polymer systems presented in this work offer materials with exceptionally high embossing capability; they are moulded easily and have a very good appearance. If necessary, the volume changes of the obtained patterns can be amended by varying the components in the polymer compound.

\section{REFERENCES}

1. Todorov N. Utilization of crude glycerol and waste poly(ethylene terephthalate) for production of unsatured polyester resins. Int J Sci Res. 2016; 5(3) 3:87-9.

2. Todorov N, Popova A. Unsaturated polyester resins based on waste products with low styrene emission. Int J Appl Res. 2016; 2(10): 86-8.

3. Todorov N, Radenkov M, Todorova D. Obtaining and studies on polymerconcrete, containing unsaturated polyester resin, based on pet waste and crude glycerol. Acad J Manag Educ. 2013;9(6): 78-85.

4. Kuo YM, Tseng HJ, Chang JE, Chao CC, Wang CT, Chang-Chein GP, et al. Stabilization of residues obtained from the treatment of laboratory waste: part 2-transformation of plasma vitrified slag into composites. J Air Waste Manage Assoc. 2011; 61(1):7884. doi: 10.3155/1047-3289.61.1.78

5. Rebeiz KS, Banko AS, Craft AP. Temperature properties of polyester mortar using fly ash waste. Practice Periodical of Hazardous, Toxic and Radioactive Waste Management. 1999; 3(3):107-11

6. Cherkezova R. (2001). Multicomponent polymer system based on hydrophilized unsaturated polyester resin and methods of obtaining it. BG Patent 63618. (in Bulgarian)

7. Cherkezova R, Radenkov Ph, Radenkov M, Hristova T, Zafirova K, Todorov N, et al. Hydrophilization of unsaturated polyester resin with sulfur, sodium hydroxide and water with a possibility for its curing in the presence of water as a solvent. J Int Sci Pub. Materials, Methods and Tehnologies. 2016;10: 487-94. 